\title{
IDENTIDAde POÉtica de Lívia Natália
}

\author{
Lívia Natália's poetic identity
}

\section{Felipe Fanuel Xavier Rodrigues}

Fundação Técnico-Educacional Souza Marques (FTESM). Rio de Janeiro, RJ, Brasil.

E-mail: felipe.rodrigues@ftesm.edu.br

\section{RESUMO}

O presente artigo oferece um estudo crítico da poesia de Lívia Natália, com foco nas características que distinguem a sua obra criativa no âmbito da literatura afro-brasileira contemporânea. Ao explorar a tematização de suas experiências, do arquivo cultural afro-brasileiro e da subjetividade negra, a leitura atenta dos poemas indica as implicações éticas de sua perspectiva poética para o contraditório contexto racial brasileiro. A articulação criativa de uma linguagem antirracista e a exploração dos sentidos de suas vivências evidenciam a complexidade da identidade poética de Natália.

PALAVRAS-CHAVE: Identidade, poesia, escritoras negras, literatura afro-brasileira contemporânea.

EDITORES:

Regina Zilberman

Gerson Roberto Neumann

SUBMETIDO: 07.12.2020

ACEITO: 04.03.2021

\section{ABSTRACT}

This article offers a critical study of Lívia Natália's poetry, focusing on the characteristics that distinguish her creative work within contemporary Afro-Brazilian literature. By investigating the thematization of her experiences, the Afro-Brazilian cultural archive, and black subjectivity, a close reading of the poems indicates the ethical implications of her poetic perspective for the contradictory Brazilian racial context. The creative articulation of an anti-racist language and the exploration of her existence's meanings speak to the complexity of Natália's poetic identity.

KEYWORDS: Identity, poetry, black women writers, contemporary Afro-Brazilian literature.

\section{COMO CITAR:}

RODRIGUES, Felipe Fanuel Xavier. Identidade poética de Lívia Natália. Revista Brasileira de Literatura Comparada, v. 23 , n. 43 , p. 20-31, mai.ago., 2021. doi: https:// doi.org/10.1590/2596$304 \times 20212343 \mathrm{ffxr}$ 
Para determinados povos, principalmente aqueles que foram colonizados, a poesia torna-se um dos lugares de criação, de manutenção e de difusão de memória, de identidade. Torna-se um lugar de transgressão ao apresentar fatos e interpretações novas a uma história que antes só trazia a marca, o selo do colonizador. É também transgressora ao optar por uma estética que destoa daquela apresentada pelo colonizador. (EVARISTO, 2010, p. 133-134).

H á nas discussões conceituais dedicadas à literatura escrita por pessoas de ascendência africana no Brasil um aspecto convergente, apesar da variação terminológica das análises desse fenômeno literário. Trata-se do relevo atribuído à historicidade do sujeito do discurso, cuja identidade intersecta sua existência como pessoa negra com a interpretação da paisagem contraditória de um contexto democrático assaz discriminatório. Tal é o caso da definição de literatura afro-brasileira como "produção literária de afrodescendentes que se assumem ideologicamente como tal, utilizando um sujeito de enunciação próprio" (LOBO, 2007, p. 315), assinalada por "uma voz autoral afrodescendente", "temas afro-brasileiros", "construções linguísticas marcadas por uma afro-brasilidade", "um projeto de transitividade discursiva", e "um ponto de vista ou lugar de enunciação política e culturalmente identificado à afrodescendência" (DUARTE, 2014, p. 29, grifos do autor). A historicidade da autoria negra também é fulcral para a caracterização de literatura negra como articulação do "eu enunciador que se quer negro" (BERND, 1988, p. 22) e para o argumento em favor do termo literatura negrobrasileira assim delineado:

A singularidade é negra e, ao mesmo tempo, brasileira, pois a palavra 'negro' aponta para um processo de luta participativa nos destinos da nação [...]. Por se tratar de participação na vida nacional, o realce a essa vertente literária deve estar referenciado à sua gênese social ativa. $\mathrm{O}$ que há de manifestação reivindicatória apoia-se na palavra 'negro' (CUTI, 2010, p. 44-45).

Nessas emblemáticas contribuições analíticas, ressalta a subjetividade negra como traço fenomenológico da arte escrita, donde a eclosão do aspecto identitário em críticas e conceitos concernentes a essa tradição literária. Para além dos ensaios de uma teorização do gênero, arejada pela heterogeneidade de produtores que raramente subscrevem a apenas uma proposta teórica para "um conceito em construção" (DUARTE, 2014, p. 29), encontra-se o autorreconhecimento da identidade e pertencimento étnico-racial de quem concebe os textos como "prática existencial", conforme aponta Miriam Alves (2010, p. 42). Às implicações ontológicas dessa prática existencial correspondem ressignificações discursivas, bem como autorrepresentações e autoafirmações de modos de ser, viver e pensar, que complicam formulações conceituais. A exemplo do critério pluralista advogado por Edimilson de Almeida Pereira em sua proposta de uma identidade literária "que precisa ser buscada também nos aspectos da forma, da visão de mundo, da interação de uma nova sensibilidade estética e social" (PEREIRA, 1995, p. 1040).

Dos variados produtos intelectuais contemporâneos da arte de inscrever a identidade negra, a Poétnica de Nei Lopes (2014) pode ter surgido como um paradigma de criação, embora pouco explorado na pesquisa literária. ${ }^{1}$ Com o gesto de "poetizar o ethnos afro com suas inflexões léxicas e suas sutis tonalidades afetivas" (SODRÉ, 2014, p. 13), Lopes contribuiu para a maturação de uma tradição

1 A obra Poétnica é uma coletânea de poesia de Nei Lopes, na qual estão reunidos todos os seus poemas escritos até 2013. 
poética assumidamente ética e étnica, inspirado por Lino Guedes e Solano Trindade. Na poétnica, a condição negra está associada às preocupações da condição humana, na perspectiva de um poeta que "se assume como sujeito, na afirmação da identidade cultural" (PROENÇA FILHO, 2004, p. 183), sendo a negritude "símbolo de libertação cultural e não conformismo social" (BROOKSHAW, 2014, p. 183). Dessa forma, a poesia se compromete a encenar o drama do lirismo sinedóquico, cuja voz reverbera experiências coletivas e estabelece novos espaços de enunciação da pessoa negra.

A etnicidade da arte poética negra reside em reapropriações criativas das tradições ancestrais provenientes de civilizações da África, que sobreviveram em solo brasileiro a contrapelo dos séculos de dominação epistêmica. Serve, pois, como um indicador histórico das inter-relações críticas entre o sujeito escritor e as interfaces do seu contexto de formação, o que materializa o caráter complexo de uma literatura que não deve ser reduzida a uma "censura prévia", quer pelo viés étnico, quer temático (PEREIRA, 1995, p. 1035). Retraduzidas em formas culturais diaspóricas, a ancestralidade africana potencializa os processos identitários, pois, como propõe Leda Maria Martins, a identidade afro-brasileira

pode ser pensada como um tecido e uma textura, nos quais as falas e gestos mnemônicos dos arquivos orais africanos, no processo dinâmico de interação com o outro, transformam-se e reatualizam-se, continuamente, em novos e diferenciados rituais de linguagem e de expressão, coreografando a singularidade e alteridades negras (MARTINS, 1997, p. 26).

Para manifestar tais singularidade e alteridades na literatura, a escrita criativa afro-brasileira documenta as vivências socio-históricas e políticas das pessoas negras. Desafiando estereótipos e noções essencialistas que preservam formas de discriminação, a pluralidade de experiências e, por conseguinte, de identidades aparece "desde o conteúdo até os modos de utilização da língua" (EVARISTO, 2009, p. 27). Além disso, como argumenta Conceição Evaristo (2008), o texto expressa versões literárias de narrativas históricas que colocam em primeiro plano os heróis negros e sua historicidade. À margem da história oficial, os sujeitos negros se apropriam da imaginação artística para reescrever a história do ponto de vista dos sobreviventes. Essa escrita de sobrevivência, capturada por Evaristo como "escrevivência”, com destaque especial para as autoras negras, decorre da autorrepresentação de corpos vivendo uma dupla condição de raça e gênero historicamente inferiorizada.

A partir da análise de Martins de que a identidade afro-brasileira é um processo de transformação e reatualização contínuas de arquivos orais africanos, pode-se pensar que esses rituais de fala e gestos mnemônicos engendram um arquivo cultural próprio. Derivado do fluxo diaspórico de culturas filosóficas, religiosas e artísticas de civilizações africanas, o arquivo cultural afro-brasileiro constitui um produto coletivo das experiências vividas pelas vítimas do tráfico transatlântico de escravizados e seus descendentes. Em suas interações com outras matrizes culturais de ascendência africana, ameríndia e europeia, os sujeitos afrodescendentes criaram um repositório de formas de expressão artística, religiosa e linguística, de cujas raízes epistemológicas dá testemunho o conjunto de vestígios dos pensamentos banto, iorubá, jeje e outros nas artes e filosofias afro-diaspóricas. No contexto de opressão, o sujeito africano escravizado reescreveu suas heranças culturais como um "migrante nu" (GLISSANT,2001, p. 16), desprovido de quaisquer outros elementos concretos da vida pré-diáspora à exceção das textualidades do corpo e da memória. Conjurando, então, um "pensamento rastro/resíduo" para ressignificar o mundo e a vida, esse sujeito criou novas formas de arte e fala (GLISSANT, 2001, p. 19). Essas criações imprevisíveis integram o que se denomina arquivo cultural afro-brasileiro, o qual 
se imbrica com a política de sobrevivência negra. Ao comentar as produções religiosas e artísticas de afrodescendentes, Achille Mbembe observa: "Para as comunidades cuja história foi sobretudo a do aviltamento e de humilhação, a criação religiosa e artística representou, muitas vezes, a derradeira fortaleza contra as forças de desumanização e de morte” (MBEMBE, 2017, p. 290).

Na poesia, a história pode ser reescrita pela semântica da identidade. Entre as produções emergentes do fazer poético afro-brasileiro, destaca-se a obra de Lívia Natália. Nascida em Salvador em 1979, Natália é professora de Teoria da Literatura na Universidade Federal da Bahia, também sua alma mater, na qual estudou teorias e críticas literárias e culturais da graduação ao doutorado. Com o seu trabalho criativo e intelectual, Natália articula múltiplos temas raciais de impactos pessoal e social que retumbam as dores e as curas, as lutas e as vitórias das vidas afrodescendentes em um falho cenário democrático com estrutura eivada de racismo. A complexidade de uma poesia íntima que intima levou Evaristo a admitir que a tarefa de prefaciar Correnteza e outros estudos marinhos, um dos volumes poéticos de Natália, era desafiadora: "Como traduzir os sentimentos que vivi ao ser tragada pelas correntezas de uma poesia que parece sustentada pelas lembranças das águas primordiais?” (EVARISTO, 2015, p. 13).

Da sua arte poética Natália apresenta a própria “Filosofia da composição”, numa economia alegórica do ensaio homônimo de Edgar Allan Poe que lhe permite teorizar a escrita literária. $\mathrm{Na}$ metapoesia do eu lírico que é invadido pelo poema, "o silêncio branco da página" torna-se "o negativo de escrever" (NATÁLIA, 2015, p. 59), como se a palavra capturasse o corpo da escritora para ser poetizada. Contudo, no momento anterior à composição artística, o seu corpo "é também uma espécie de inferno", pois “[z] umbe o mundo em brasas na cabeça do poeta” (idem). Dessa conclusão universal, a voz poética alcança a personificação da poesia:

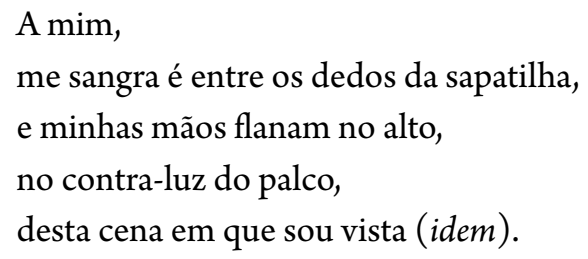

Expressa na escrita de um corpo em performance, com dedos dos pés sangrando e mãos flanando na parte não iluminada do proscênio, a poesia se encena para ser vista, tal como uma dança ritual. As imagens corporais refletem a condição sociopolítica da poeta negra, cujo corpo ocupa posição a priori em relação à arte em uma sociedade que discrimina gênero e raça. Como hermeneuta da própria poesia, Natália reescreve essa história de discriminação com a sutil ambiguidade do último verso para demandar reflexão crítica no que tange aos espaços em que o corpo feminino negro se faz presente de modo socialmente transformador.

A visibilidade da mulher negra em diversos âmbitos de atuação, fala e poder, tais como a escrita literária, confronta os estereótipos que na estrutura social brasileira historicamente funcionam para limitar a sua subjetividade, segundo desenreda Natália: 
Tendo sido o nosso corpo aquele que prioritariamente definia o nosso lugar e função, a leitura que faziam da cor da nossa pele que nos colocava em determinado lugar, por isso é esperável que não se costume pensar no poder que carregamos nas nossas mentes (NATÁLIA, 2016a, p. 112).

À hermenêutica epidérmica do racismo brasileiro Natália responde com o movimento libertador de um corpo que nega a heteronomia dos contingentes papéis sociais que as mulheres negras desempenham, sendo o trabalho doméstico um epítome da condição subalterna. Para Lélia Gonzalez, as raízes do trabalho doméstico estão na servidão das mulheres escravizadas (mucamas) na Casa Grande colonial, em que, além de cozinhar, lavar, passar, limpar, cuidar da casa e das crianças, eram obrigadas a prestar serviços sexuais a seus senhores, donde o significado etimológico de mucama como amante escravizada. Gonzalez capta a ambivalência dessa representação social da mulher negra, ao afirmar que "a empregada doméstica só faz cutucar a culpabilidade branca, porque ela continua sendo mucama com todas as letras. Por isso ela é violenta e concretamente reprimida" (GONZALEZ, 2019, p. 247). Essa histórica privação da autonomia das mulheres negras evidencia o racismo estrutural que mina sua integridade $\mathrm{e}$ enfraquece ideais democráticos. Evidências desse racismo estrutural aparecem nas páginas da literatura brasileira tout court contemporânea, cujas personagens femininas negras são minoria e tendem a ser representadas como empregadas domésticas e prostitutas (DALCASTAGNÈ, 2017). Com seu talento criativo e sua produção intelectual, Natália se propõe a "[f]urar o bloqueio do racismo institucional com o corpo" para não "mimetizar a subalternidade na construção do pensamento" (NATÁLIA, 2016a, p. 119).

Em “Sobre a poeta", Natália exprime os desdobramentos íntimos de sua (meta)poesia. Anunciado no título, o ofício de poeta - femíneo como o elegante artigo definido 'a' - versa sobre "pedras que me enfeitam a travessia" e "entranham seus dentes nos meus pés" (NATÁLIA, 2015, p. 119). Diante dessas pedras drummondianas, causadoras de permanentes dores existenciais, resta à voz em versos conversar sobre o seu quefazer. Afinal, como inquirido em "Desventura": "Que mais pode um poeta fazer das pedras,/ senão cantá-las" (NATÁLIA, 2015, p. 33). Uma investigação interna do gênero espelha um autoexame da subjetividade, como indicam as seguintes estrofes de "Sobre a poeta":

Sangro em silêncio e sem pressa

apenas porque sangrar é minha ciranda,

minha dança feminina,

meu ritual.

O sal das Águas macera meu corpo

e as algas ligeiras persistem em meus cabelos.

Os peixes bebem de minhas lágrimas

Enquanto teço mais uma pérola macia.

Colho espinhos em vez de rosas,

adoeço, durmo a morte das horas,

não sinto fome. Minha saúde vacila

e a palavra não sana o que sangra (NATÁLIA, 2015, p. 119). 
Das imagens atribuídas à poesia poucas contêm uma carga semântica tão expressiva quanto o verbo sangrar. Como nota Evaristo, eis "o sujeito poético - mulher -, cumprindo a sua Sina de sangrar, enquanto ela mesma - sujeito de autoria - cumpre outro destino: o de poetar" (EVARISTO, 2015, p. 14). Símbolo de feminilidade, sangrar representa a circularidade da vida, cujo potencial generativo se renova no ciclo menstrual. Por isso, a aliteração sangrar e singrar eclode no poema "Sina": "Todo mês eu sangro./ Todo mês eu singro este mar,/ em que me banho” (NATÁLIA, 2015, p. 23). Em “Sobre a poeta", ao percorrer ritualmente essa ciranda feminina, o corpo negro encara sua lide como uma ostra que se defende produzindo pérolas quando parasitas invadem o seu corpo.

Entretanto, sangrar também denota dores que persistem na "morte das horas". Cabe à palavra exibir feridas, mas não as sanar, como confessado em "Este ofício de poeta": "Palavra, afeto difícil./ Silêncio, lugar impossível” (NATÁLIA, 2017a, p. 51). Em meio à quantidade de medicamentos, refeições, horas de sono, sessões de fisioterapia, quilos e livros, referentes às "contas que devoram os dias" (NATÁLIA, 2015, p. 119), conforme a última estrofe de "Sobre a poeta", a voz poética sente enquanto pensa, revelando-se demasiadamente humana. Apenas o tempo, com seus movimentos curvilíneos diários, é apto para curar, como afirma o poema "Cura": "O tempo, como um cão,/ cura as feridas na saliva dos dias" (NATÁLIA, 2015, p. 147).

O tempo rememora o passado, ao ressignificar o presente. Esse exercício mnemônico característico das culturas afro-diaspóricas se observa no poema "Metonímia”, no qual Natália descreve "um barquinho", que seu pai batizou em sua homenagem. A poeta encontra o significado de sua poética no simples movimento de um pequeno barco na água. Como um tropo de sua arte, o barco de pesca do pai tem importância por causa do nome.

Meu pai colocou meu nome num barquinho que comprou.

É miúdo.

Uma insignificância no meio do oceano de vaga vaga.

É reles.

De uma cruel e desleixada vileza.

De uma pequenez quase lírica.

É reles.

Mal cabem nele dois homens e o isopor para a pescaria.

Mal cabem dois homens.

Talvez somente ele - solitário - e o isopor.

Mas, como no milagre,

o barco que leva o meu nome caminha sobre as águas (NATÁLIA, 2016b, p. 17). 
Título do poema, a palavra metonímia vem do grego meta-, que significa mudança e onyma, que conota nome, logo o sentido literal de metōnymia ser mudança de nome. Na estética de Natália, a existência tem um sentido metonímico que simboliza a pequenez do lirismo, representado por um barco vagando no meio do oceano. A detalhada imagem do barco que leva o pai solitário para pescar com uma caixa de isopor se torna insignificante diante da epifania de seu movimento sobre as águas, configurando-se um comentário à sobrevivência milagrosa do nome, emblema identitário. A aporia do nome Lívia (lívida) Natália (nascimento) reforça o simbolismo da identidade. Com o símile ao milagre de Jesus andando sobre as águas, estabelece-se o tempo mítico no qual o barco deixa sua condição insignificante para carregar significativamente a identidade e navegar pelas águas turbulentas do mundo. Dessa jornada de autocompreensão, apreende-se a confluência de memória individual e memória social ${ }^{2}$ na construção do que Evaristo compreende como "mística negra":

A literatura afro-brasileira traz o registro de uma memória social, enquanto lembranças de vários
indivíduos. Memória que permitiu um conhecimento de um sistema simbólico, que possibilitou uma
reorganização do território negro da diáspora, através de uma mística negra, vivida em um tempo que
escapa a uma medição cronológica, por se tratar de um tempo mítico (EVARISTO, 2008, p. 4).

Além disso, o barco possui um significado mítico no candomblé. Em rituais de iniciação, a palavra barco comunica o compromisso do iniciado com divindades africanas, ou seja, os orixás. De acordo com Mãe Beata de Yemonjá (2010), esse barco ritual também alude aos navios negreiros que transportaram corpos africanos e sua espiritualidade para os territórios da diáspora. Em sua obra, Natália explora o acervo cultural da espiritualidade afro-brasileira para celebrar sua negritude e herança africana.

Esse é o caso da descrição da água do rio em seu poema “Ori”. O rio representa Oxum, a deusa iorubá da água doce. Como o título sugere, o eu poético atribui a Oxum o seu Ori (ou Cabeça), entendido como um princípio filosófico e ético de vida. Para uma poeta iniciada no culto a Oxum, há uma estreita ligação entre água e vitalidade: "Um rio não caminha só,/ ele atravessa:/ rasga pedras e fere o chão com sua correnteza translúcida” (NATÁLIA, 2016b, p. 31).

Ao usar verbos de ação para expressar o movimento da água do rio, Natália traduz as narrativas ancestrais do eu divino em imagens poéticas vívidas. Marca de dores, as pedras são rasgadas pela força mítica do movimento aquático, que, como retratado nas outras estrofes, inclui uma dança de água potável dentro dos corpos, margens lamacentas de rios, torrentes violentas e uma bela negra dançando na água. No fundo do rio, pulseiras e perfumes denotam o mistério de sua beleza. Mesmo quando a água para, há vida e encanto, como a luz dourada das lagoas e os peixes testemunham. Com a personificação do rio, reino imagético de Oxum, visualiza-se a potencialidade das narrativas sagradas de origem africana para empoderar a fala poética de sujeitos negros. Como nota Evaristo, a poesia de Natália abrange "um teor celebrativo de uma memória ancestral e histórica negra", bem como "a assunção de uma identidade negra" e um "orgulho étnico" (EVARISTO, 2015, p. 15), equivalente à "assunção da etnia” verificada na poética de Lopes (PROENÇA FILHO, 2004, p. 183).

\footnotetext{
2 Para Maurice Halbwachs, a memória do indivíduo só pode ser compreendida dentro do pensamento do grupo correspondente, pois a memória individual é "uma parte ou um aspecto da memória de um grupo" (HALBWACHS, 1992, p. 53). Em diálogo com Halbwachs, Conceição Evaristo reconhece que a memória individual "é antes de tudo uma memória social”, sendo que a interação entre memória individual e memória social se completa pela linguagem (EVARISTO, 2008, p. 4).
} 
Constatam-se os trágicos reflexos sócio-políticos da condição negra no horror da funesta violência policial contra pessoas negras no Brasil, tendo a morte de João Alberto Silveira Freitas por seguranças em um mercado em 2020 repercutido mais um caso de uma prática genocida. No título do poema de linguagem aguda "111 tiros, 111 presos, 111 negros”, Natália faz alusão ao massacre do Carandiru em 1992, em São Paulo, quando 111 presos foram mortos durante uma operação policial para conter um motim na prisão. 111 é também o número de tiros que quatro policiais dispararam contra cinco meninos negros desarmados no Rio de Janeiro em 2015. Epigrafado por um trecho da canção "Haiti" de Caetano Veloso e Gilberto Gil, o poema ecoa a aliteração tragicamente literal entre substantivo e adjetivo, os presos e pretos: "Porque os presos são quase todos pretos" (NATÁLIA, 2016b, p. 93). Efeito de uma histórica brutalidade racial, a chacina é particularizada, haja vista a ameaça à sobrevivência dos sujeitos negros que as mortes representam. Na primeira estrofe, anuncia-se, por um olhar escatológico voltado para o amanhã, o êxito da barbárie racista na sociedade, que com o extermínio de cada vida negra, se afasta de qualquer promessa civilizatória:

\author{
Amanhã uma bala perdida atingirá meu peito. \\ Serei apenas outra negra perdida \\ Ante a bala encontrada. \\ Das viaturas, gritarão que transportávamos droga, \\ Que atiramos com armamento pesado, \\ Que reagimos e tombamos (NATÁLIA, 2016b, p. 93).
}

Em seu peito, a voz poética reconhece "uma bala perdida” como "a bala encontrada”, capaz de condicionar a sua subjetividade ao status de "negra perdida”. A repetição do adjetivo perdida enfatiza o caráter inferior atribuído à pessoa negra, cuja trajetória ocorre no fogo cruzado dos projéteis atirados a esmo para encontrar o alvo do genocídio racialmente motivado. Com o discurso indireto, o poema apresenta as táticas retóricas empregadas para justificar as letais ações policiais, arrematando o desfecho da guerra unilateral com o verbo reagir como causa de tombar.

Para compreender a estrutura racista que gera a situação verossímil, é preciso observar as contradições raciais do contexto brasileiro. Graças à ideologia nacional revisionista que prega a coexistência pacífica entre senhores de escravos e pessoas escravizadas na colonização, o Brasil se fez conhecido como uma democracia racial. Canonizada pela publicação de Casa Grande e Senzala de Gilberto Freyre em 1933, a ideologia provou-se um embuste para se negar a existência do racismo no país, embora tenha servido para redimir o fenômeno da miscigenação, outrora visto como sinal de atraso. Ao denunciar que a miscigenação resultou do estupro da mulher negra, Abdias do Nascimento (1984) decodificou a ideologia como mais uma das várias estratégias racistas destinadas à institucionalização da violência contra brasileiros negros. A esse "genocídio" racial identificado por Nascimento (2018) correspondem as estatísticas oficiais indicando que o negro tem 2,7 vezes mais chances de ser assassinado no Brasil (CERQUEIRA et al., 2020). Daí Natália comprometer a metalinguagem com o conteúdo em "Da inutilidade da poesia": 
63 jovens negros são mortos por dia.

23 mil jovens negros são mortos por ano.

Ao menos um morreu agora,

enquanto você lia este poema (NATÁLIA, 2017a, p. 73).

Conceito abstrato, os números na poética de Natália são empregados como artifício imagético que concretiza existências, demandando reflexão crítica e provocando catarse na leitura. Em "111 tiros, 111 presos, 111 negros”, o recurso numérico também pode ter efeito visual concreto de grades carcerárias e armas, além de alegorizar a singularidade de cada uma das vítimas da violência.

As duas estrofes seguintes realizam uma necropsia poética dos corpos negros tombados por tiros policiais. Concretiza-se o horror do "Dantesco tombadilho" celebrado por moscas e urubus "dançando em espirais" (NATÁLIA, 2016b, p. 93). Questiona-se a impotência diante do silenciamento violento de corpos e da marginalização dos sujeitos pretos. Fatos que comprovam o que Mbembe (2003) classifica como "necropolítica" para decifrar o poder da morte que historicamente subjuga a vida.

Nas últimas quatro estrofes, o sintagma "Reagimos, sim!" (NATÁLIA, 2016b, p. 93) rege a voz poética narradora de possíveis histórias de desobediência social. Trata-se de um ensaio de reação que inclui a iconoclastia das imagens racistas, tais como a mulher que confunde a mulher negra com a empregada, o segurança que persegue o homem negro no mercado, as sinhazinhas em suas casas. Essa atitude antirracista é assumida para se reparar os danos da dívida colonial, numa proposta de negociação ética: "Se a casa grande nos deve até a alma/ Que comecem os jogos, que paguem com o que se paga” (NATÁLIA, 2016b, p. 94).

Na poesia, instaura-se a exigência ética de reparação e restituição, passo fundamental para romper com a lógica de um processo histórico habituado à morte de pessoas afrodescendentes. Com a sistemática violência física e psicológica, o sujeito negro foi submetido a quase quatro séculos de exploração de sua mão de obra. Desse legado da escravidão persistem práticas violentas que servem ao propósito político de dominar suas vidas. Por extensão, o convite à reação no poema de Natália - "Precisamos reagir" (idem) - convoca a todos os brasileiros para uma libertação ética de suas chagas racistas, juntando-se à ininterrupta luta dos sujeitos negros por justiça. A efetivação desse gesto transformador ocasiona o reencontro redentor da condição humana no reconhecimento do outro. Mbembe afirma:

\footnotetext{
A ética da restituição e da reparação implica por conseguinte o reconhecimento daquilo a que podemos chamar a parte do outro, que não é a minha, e da qual eu sou no entanto o garante, quer queira quer não. Esta parte do outro não posso açambarcá-la sem consequência para a ideia de si, da justiça, do direito, em suma, da Humanidade, ou ainda para o projeto universal, se for este efetivamente o seu destino final (MBEMBE, 2017, p. 304-305).
}

Enquanto a ética da restituição e da reparação ainda habita o reino da possibilidade, a poeta aprofunda a investigação de suas dores. Em "Anatomia das pedras", Natália disseca o percurso de suas feridas e sua relação com o talento criativo. Anunciada no título, a palavra "pedras" não aparece nos versos, sabendo-se, todavia, que essa carrega o sentido da recorrente temática da "dor da solidão" (EVARISTO, 2015, p. 15). Assim se lê na primeira parte do poema: 


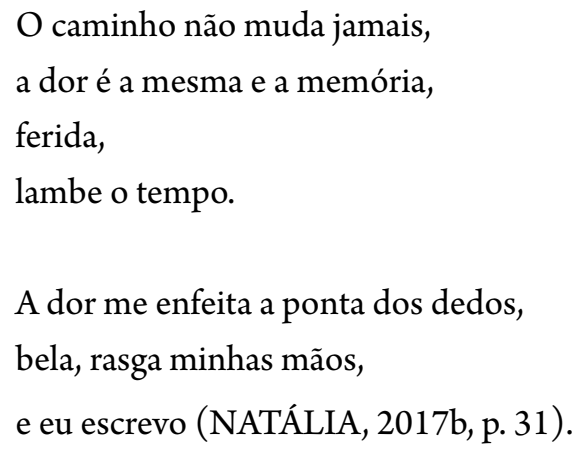

O eu lírico evoca a constância da dor vivida e revivida nas curvas do tempo. Ao sentir a dor do passado no presente com a memória individual, a voz poética se prepara para a escrita. Conflui com o material mnêmico a presença da dor nos dedos e mãos, instrumentos da composição poética. Logo, a dor desvela a sua beleza como ato anterior ao gesto de escrever.

A leitura da segunda parte do poema indica que a escrita convive com a dor de modo dialético. Da floresta escura a animais estranhos, dia lacrimoso, olhos mortos, ausência e escuridão, o lirismo reencena a arte de navegar os meandros do tempo: "Os dias passam e eu navego nas horas/ as palavras jogam com o gesto" (idem).

Em seu doloroso gesto de poetar, Natália examina a intimidade de suas experiências para alcançar a autognose. Sua anatomia poética das dores singulariza o significado de suas vivências bem como atravessa as fronteiras da escrita e da autorrepresentação. Central para a poesia, a subjetividade cartografa os sentidos de um corpo que "não é apenas descrito, mas antes de tudo vivido" (EVARISTO, 2005, p. 204).

A análise da obra poética de Lívia Natália contribui para amplificar a visão acerca do uso da arte literária como estratégia discursiva no processo de reivindicar a reparação ética dos danos provocados pela longa história de discriminação de pessoas negras no Brasil. Para a construção desse amplo entendimento, contribui sua articulação criativa de uma linguagem antirracista, aliada à apropriação simbólica do arquivo cultural afro-brasileiro e à exploração dos sentidos da condição negra. Ao demandar engajamento crítico na leitura, seus textos produzem impacto sociopolítico, sobretudo por se tratar de poesia que tematiza as contradições raciais do contexto.

$\mathrm{Na}$ enunciação de suas vivências, a poeta privilegia um percurso íntimo que sublinha a semântica da subjetividade e historiciza a identidade de mulher negra. Contrariando expectativas essencialistas, a poesia intima por afirmar a plenitude da existência afrodescendente, sem o reducionismo epistêmico de termos predefinidos. Para tal, seu léxico criativo desmantela platitudes racistas com a palavra refletida e reflexiva, cuja autoridade moral se legitima na escrita.

Com seu texto poético, Natália ocupa os lugares do discurso de si, do outro e de sua arte. $\mathrm{Na}$ metalinguagem, enseja-se o manifesto de uma identidade literária engendrada na afluência de sentidos da vida. De tal fala afiada, potente e liberta, espera-se voo alto: "As palavras afirmam o que mesmo são:/ sombras de pássaros" (NATÁLIA, 2015, p. 73). 


\section{REFERÊNCIAS}

ALVES, Miriam. BrasilAfro autorrevelado: literatura brasileira contemporânea. Belo Horizonte: Nandyala, 2010 .

BEATA DE YEMONJÁ, Mãe. Sob o manto dos orixás. In: COSTA, Haroldo. Mãe Beata de Yemonjá: guia, cidadã, guerreira. Rio de Janeiro: Garamond; Fundação Biblioteca Nacional, 2010, p. 75-82.

BERND, Zilá. Introdução à literatura negra. São Paulo: Brasiliense, 1988.

BROOKSHAW, David. Orelha do livro Incursões sobre a pele. In: LOPES, Nei. Poétnica. Rio de Janeiro: Mórula, 2014, p. 183-184.

CERQUEIRA, Daniel et al. (eds.). Atlas da violência 2020. Rio de Janeiro: IPEA, 2020.

CUTI [Luís Silva]. Literatura negro-brasileira. São Paulo: Selo Negro, 2010.

DALCASTAGNÈ, Regina. Entre silêncios e estereótipos: relações raciais na literatura brasileira contemporânea. In: EBLE, Laeticia Jensen; DALCASTAGNÈ, Regina (orgs.). Literatura e exclusão. Porto Alegre: Zouk, 2017, p. 217-238.

DUARTE, Eduardo de Assis. Por um conceito de literatura afro-brasileira. In: Literatura afro-brasileira: 100 autores do século XVIII ao XXI. Rio de Janeiro: Pallas, 2014, p. 17-45.

EVARISTO, Conceição. Escrevivências da afro-brasilidade: história e memória. Releitura, Belo Horizonte, Fundação Municipal de Cultura, n. 23, Novembro, 2008, p. 1-17.

EVARISTO, Conceição. Literatura negra: uma poética de nossa afro-brasilidade. SCRIPTA, Belo Horizonte, v. 13, n. 25, p. 17-31, 20 sem. 2009.

EVARISTO, Conceição. Literatura negra: uma voz quilombola na literatura brasileira. In: PEREIRA, Edimilson de Almeida Pereira (org.). Um tigre na floresta de signos: estudos sobre poesia e demandas sociais no Brasil. Belo Horizonte: Mazza, 2010, p. 132-142.

EVARISTO, Conceição. Lembranças das águas primordiais. In: NATÁLIA, Lívia. Correntezas e outros estudos marinhos. Salvador: Ogum's Toques Negros, 2015, p. 13-17.

GLISSANT, Édouard. Introdução a uma poética da diversidade. Trad. Enilce Rocha. Juiz de Fora: UFJF, 2013.

GONZALEZ, Lélia. Racismo e sexismo na cultura brasileira. In: HOLLANDA, Heloisa Buarque de (org.). Pensamento feminista brasileiro: formação e contexto. Rio de Janeiro: Bazar do Tempo, 2019, p. 237-256.

HALBWACHS, Maurice. On collective memory. Trad. Lewis Coser. Chicago: University of Chicago Press, 1992.

LOBO, Luiza. Crítica sem juízo. 2a. ed. Rio de Janeiro: Garamond, 2007.

LOPES, Nei. Poétnica. Rio de Janeiro: Mórula, 2014.

MARTINS, Leda Maria. Afrografias da memória. Belo Horizonte: Mazza, 1997.

MBEMBE, Achille. Necropolitics. Trad. Libby Meintjes. Public Culture, v. 15, n.1, p. 11-40, 2003. 
MBEMBE, Achille. Crítica da razão negra. 2a. ed. Trad. Marta Lança. Lisboa: Antígona, 2017.

NASCIMENTO, Abdias do. Jornada negro-libertária. Rio de Janeiro: IPEAFRO, 1984.

NASCIMENTO, Abdias do. O genocídio do negro brasileiro: processo de um racismo mascarado. 4. ed. São Paulo: Perspectivas, 2018.

NATÁLIA, Lívia. Correntezas e outros estudos marinhos. Salvador: Ogum’s Toques Negros, 2015.

NATÁLIA, Lívia. Intelectuais negras e racismo institucional: um corpo fora de lugar. In: LIMA, Elizabeth Gonzaga; GONÇALVES, Luciana Sacramento Moreno; CORDEIRO, Verbena Maria Rocha (orgs.). Leitura e literatura: entre vozes, livros e redes. Campinas: Pontes, 2016a, p. 111-121.

NATÁLIA, Lívia. Água negra e outras águas. 2a. ed. Salvador: Caramurê, $2016 \mathrm{~b}$.

NATÁLIA, Lívia. Sobejos do mar. Salvador: Caramurê, 2017a.

NATÁLIA, Lívia. Dia bonito pra chover. Rio de Janeiro: Malê, 2017b.

PEREIRA, Edimilson de Almeida. Panorama da literatura afro-brasileira. Callaloo, v. 18, n. 4. John Hopkins University Press, 1995, p. 1035-1040.

PROENÇA FILHO, Domício. A trajetória do negro na literatura brasileira. Estudos Avançados, v. 18, n. 50, 2004, p. 161-193.

SODRÉ, Muniz. Implicando Nei Lopes. In: LOPES, Nei. Poétnica. Rio de Janeiro: Mórula, 2014, p. 11-13. 